\title{
Farklı Sulama Suyu Tuzluluk Seviyelerinin Bazı Silajlık Sorgum (Sorgum sp.) Çeşitleri Üzerine Etkileri*
}

\author{
İbrahim ARAS ${ }^{1}$, Bilal KESKIN $^{2}$
}

ÖZET: Araştırma 2015 yılında Iğdır Üniversitesi Tarımsal Araştırma ve Uygulama Merkezi denem alanlarında faktöriyel deneme desenine göre 4 tekerrürlü olarak kurulmuştur. Araştırma seralarda saksılarda yetiştirilen 3 Sorgum (Rox, Early Sumac, Leoti), 2 sorgum-sudan otu melezi (Nutri Honey, Hayday) ve 1 Sudan otu (Gözde 80) çeşitlerinin bitki boyu, bitki yaş a ğırlı̆̆ oranı, salkım oranına 7 farklı sulama suyu tuzluluk oranlarının $\left(0,3,6,9,12,15,18 \mathrm{dS} \mathrm{m}^{-1}\right)$ etkilerini belirlemek amacıyla kurulmuştur. Sulama suyu tuzluluğu arttıkça, bitki boyu, bitki yaş ağırlığı, bitki kuru ağırlığı, tuza tolerans yüzdesi ve salkım oranı düşmüş, bitki kuru oranı, yaprak oranı ve gövde oranı ise artmıştır. En yüksek tuzlu su uygulamasına en dayanıklı sorgum çeşitlerinin sırasıyla Early sumac, Rox ve Nutri honey, en hassas çeşitlerin ise sırasıyla Leoti, Gözde-80 ve Hayday olduğu görülmüştür.

Anahtar Kelimeler: Sorgum, tuzlu su, verim, tuza tolerans yüzdesi

\section{The Effects of Different Irrigation Water Salinity Levels on Some Silage Sorghum (Sorghum sp.) Varieties}

\begin{abstract}
The research was established with 4 replications according to the factorial experiment design in the research areas of the Agricultural Research and Application Center of Igdir University in 2015 year. The study was set up to determine the effects of plant height, plant fresh weight, plant dry rate, plant dry weight, salt tolerance percentage, leaf ratio, stem ratio and bunch rate of sorghum of 7 different irrigation water salinity $(0,3,6,9,12$, $15,18 \mathrm{dS} \mathrm{m}^{-1}$ ) on 3 sorghum (Rox, Early Sumac, Leoti) 2 sorghum-sudangrass hybrids (Nutri Honey, Hayday) and 1 Sudangrass (Gözde-80) grown in pots in greenhouses. As the irrigation water salinity increased, the plant height, plant fresh weight, plant dry weight, salt tolerance percentage and bunch rate decreased, plant dry ratio, leaf ratio and stem ratio increased. The most resistant varieties of sorghum to the highest saline application were Early Sumac, Rox and Nutri Honey, respectively and the most sensitive varieties were Leoti, Gözde-80 and Hayday, respectively.
\end{abstract}

Keywords: Sorghum, salinity water, yield, salt tolerance percentage

İbrahim ARAS (0000-0001-7078-7097), Aralık İlçe Milli Eğitim Müdürlüğü, Iğdır, Türkiye

Bilal KESKİN (0000-0001-6826-9768), Iğdır Üniversitesi, Ziraat Fakültesi , Tarla Bitkileri, Iğdır, Türkiye

Sorumlu yazar/Corresponding Author: Bilal KESKİN, bilalkeskin66@yahoo.com

Bu çalışma İbrahim ARAS'ın Yüksek Lisans tezinin bir bölümüdür. 


\section{GİRiş}

Kaba yem açı̆̆ının karşılanması amacıyla, son yıllarda gerek su isteği gerekse toprak yapısı bakımından kısıtlı imkânları daha iyi bir şekilde kullanarak daha tatmin edici üretime olanak tanıyan bitkiler gündeme gelmektedir. $\mathrm{Bu}$ anlamda hayvan besleme ve endüstri alanındaki öneminin her geçen gün artması, yüksek verimli ve daha kaliteli melez çeşitlerin geliştirilmesi ve adaptasyon sınırlarının genişliği nedeniyle diğer ülkelerde önem kazanmaya başlayan sorgumlar bu noktada yazlık olarak yetiştirilebilecek diğer bir kaba yem kaynağı olarak ön plana çıkmaktadır. Birçok serin ve 1 lık mevsim yem bitkilerinin yüksek sicaklıklar ve yetersiz yağışlar nedeniyle dormant olduğu ve sararıp kuruduğu yaz aylarında kaliteli ve besleme de ğeri yüksek yemler üretmektedirler (Fribourg et al., 1976). Sorgum x sudan otu melezleri hayvancılığı gelişmiş ülkelerde süt sığırı işletmelerinin en önde gelen yem bitkilerinden biridir (Skerman and Riveros, 1990; Sağlamtimur ve ark, 1998).

Özellikle kurak ve yarı kurak iklim bölgelerinde, sulu tarım için doğal kaynakların azalması veya kirlenmesi, düşük kaliteli sulama suyu ile sulama yapmak zorunda kalınması, genellikle üretim yapılan bölgelerin tuzlanmasına ve üretim dışı kalmasına neden olmuştur. Dünyada tuzlu sular kullanılarak toprakta ve bitkide zarar meydana getirmeden yetiştiriciliğin yapılması amacıyla araştırmalar tüm hızıyla devam etmektedir. Sulama suyu ve toprak tuzluluğu bitkilerde büyüme ve gelişmeyi, olumsuz yönde etkilediği gibi ürünün kalitesini de önemli ölçüde düşürmektedir (Parlak ve Parlak, 2005).

Tuzluluk, özellikle kurak ve yarı-kurak alanlarda tarımsal üretimi kısıtlayan en önemli problemlerden birisidir. Dünya'da 831 milyon hektar alanda tuzluluk problemi söz konusuyken (Beltran and Manzur, 2005), Türkiye'de 1.5 milyon hektar alanda hem tuzluluk hem de alkalilik problem oluşturmaktadır (Güngör ve Erözel, 1994).

Tuzlu toprakların iyileştirilmesi için uygulanan ıslah yöntemleri zaman alıcı ve oldukça pahalı olduğundan; bu alanlarda yetişebilen, tuzluluğa toleransl1, ekonomik olarak yetiştirilebilecek bitki tür veya çeşitlerinin geliştirilmesi ve kullanımı önemli bir strateji olarak dikkate alınmaktadır (Shannon, 1978; Epstein, 1985; Ashraf, 1994; Temel et al., 2015). Sorgum (Sorghum bicolor L. Moench) tuzluluğun yoğun şekilde yaşandı ğ 1 kurak ve yarı-kurak alanlara adapte olmuş, tuzluluğa orta derecede toleranslı bir C4 bitkisidir (Francois et al., 1984; Maas et al., 1986; Nawaz et al., 2010). Sorgum aynı zamanda kuraklığa ve yüksek sıcaklığa toleranslıdır (Pholsen et al., 1998; Berenguer and Faci, 2001; Khalili et al., 2008). Sorgumun bu özelliğgi, özellikle tuzluluğun potansiyel bir problem olduğu kurak ve yarı-kurak alanlarda ekim potansiyeli olduğunu göstermekte ve bu alanlarda yetiştirilebilecek sorgum çeşitlerinin tuzluluğa tepkilerinin bilinmesinin gerekliliğini ortaya koymaktadır.

Bu çalışmada, yedi farklı sulama suyu tuzluluğu $\left(0,3,6,9,12,15,18 \mathrm{dS} \mathrm{m}^{-1}\right)$ 'nun üç çeşit Sorgum (Rox, Early sumac, Leoti), 2 çeşit Sorgum x Sudan otu melezi (Nutri honey, Hayday) ve bir çeşit Sudan otu (Gözde 80)'nun verim ve verim komponentlerine etkileri araştırılmıştır.

\section{MATERYAL VE YÖNTEM}

Araştırma 2015 yılında Iğdır Üniversitesi Tarımsal Araştırma ve Uygulama Merkezi Müdürlüğüne bağlı çiftlik arazisindeki seralarda yürütülmüştür. Araştırmada Rox, Early sumac ve Leoti (Silajlık sorgum (Sorghum bicolor L.)), Nutri honey ve Hayday (Silajlik sorgum x Sudan otu melezi (Sorghum bicolor $x$ Sorghum sudanense) ve Gözde 80 (Sudan otu (Sorghum sudanense)) çeşitleri kullanılmıştır.

Araştırma Tesadüf parsellerinde faktöriyel deneme desenine göre 4 tekerrürlü olarak kurulmuştur. Araştırmada $35 \mathrm{~cm}$ çapında ve $30 \mathrm{~cm}$ derinliğinde plastik ve siyah renkte saksılar kullanılmıştır. Drenajı sağlamak için saksıların dip kısımlarına ortalama 3-5 cm olacak şekilde kum konulmuş ve saksının üst kısmında $5 \mathrm{~cm}$ boşluk kalacak şekilde killi tınlı bünyeye sahip toprakla doldurulmuştur. Her saksıya 3 adet tohum gelecek şekilde toplam 168 saksıya tohum ekimleri 09.07.2015 tarihinde 
gerçekleştirilmiştir. Bitki çıkışları 16.07.2015 tarihinden itibaren başlamıştır. Bitkiler 01.08.2015 tarihinde belirgin hale geldikten sonra yabanc1 ot mücadelesi ve daha sonra seyreltme işlemi yapılarak her saksıda sadece 1 adet bitki bırakılmıştır.

Saksılara konulan topraklar Iğdır Üniversitesi Ziraat Fakültesi Laboratuvarlarında analiz edilmiştir. Saksı toprağı killi-tınlı tekstüre sahip olup, $\mathrm{pH} 8.71$, EC değeri $1.10\left(\mathrm{dS} \mathrm{m}^{-1}\right)$ 'dir. Kireç \%18.64, organik madde \%1.04, kalsiyum $3254.67 \mathrm{ppm}$, potasyum $255.00 \mathrm{ppm}$, magnezyum $495.00 \mathrm{ppm}$, sodyum $259.33 \mathrm{ppm}$, azot $\% 0.05$, fosfor $34.67 \mathrm{ppm}$, tarla kapasitesi \%29.13, solma noktas $1 \% 12.82$, faydalı su $\% 16.31$ olarak tespit edilmiştir.

Saksılardaki tohumlar çimlenip 5-6 $\mathrm{cm}$ boyuna ulaşana kadar normal kuyu suyuyla sulanmıştır. Daha sonraki sulamalar $\mathrm{NaCl}$ (sodyum klorür), $\mathrm{CaCl}_{2}$ (Kalsiyum klorür) ve $\mathrm{MgSO}_{4}$ (Magnezyum sülfat) tuzları birlikte kullanılarak 7 farklı sulama suyu tuzluluğu $\left(0,3,6,9,12,15\right.$, ve $\left.18 \mathrm{dS} \mathrm{m}^{-1}\right)$ elde edilmiştir. Tuzlu suların hazırlanması aşamasında, toprağın fiziksel özellikleri üzerine olan etkilerinin benzer olmasından ötürü $\mathrm{Ca} / \mathrm{Mg} 1 / 1$ oranında kullanılmıştır (Poonia and Pal, 1979). Sulama suyunun EC değerleri Iğdır Üniversitesi Ziraat Fakültesi Laboratuvarlarında ölçülmüştür.

Saksıların sulamaları Tarımsal Uygulama ve Araştırma Merkezi bünyesinde yer alan kuyulardan sağlanan suyla sulama yapılmıştır. Kuyu suyunun tuzluluk değeri Ziraat Fakültesi Laboratuvarlarında EC değeri olarak 1.043 (dS $\left.\mathrm{m}^{-1}\right)$ ölçülmüsşür. Bitkilerin sulama zamanları "Toprak su potansiyeli ölçme cihazıyla" belirlenmiştir. Topraktaki kullanılabilir su düzeyi \%50'ye düştüğünde sulamaya başlanılmıştır. Ekimle birlikte her bir saksiya dekara $8 \mathrm{~kg}$ azot $(\mathrm{N})$ ve $8 \mathrm{~kg} \mathrm{P}_{2} \mathrm{O}_{5}$ (fosfor) gelecek şekilde gübre uygulanmıştır. Ayrıca bitkiler 30 günlük gelişme dönemlerinin sonunda dekara $8 \mathrm{~kg}$ azot $(\mathrm{N})$ gelecek şekilde saksılara ilave azot gübresi uygulanmıştır. Gübre olarak amonyum nitrat ve triple süper fosfat kullanılmıştır. Saksılardaki bitkiler 90 (doksan) günlük gelişmelerinin ardından 06.10.2015 tarihinde hasat işlemlerine başlanılmıştır. Bitki boyu toprak yüzeyinden salkım ucuna kadar olan mesafesi $\mathrm{cm}$ olarak ölçülmüştür. Bitki yaş ağırlığı toprak seviyesinden $5 \mathrm{~cm}$ yükseklikte biçilerek yaş olarak tartılmıştır. Bitki kuru ot oran $170{ }^{\circ} \mathrm{C}$ ayarlı kurutma dolabında ağırlıkları sabitleşinceye kadar kurutulmuş ve bitki yaş ağırlığına oranlanarak belirlenmiştir.

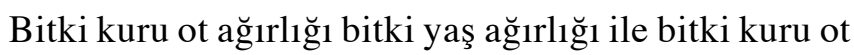
oranı çarpılarak belirlenmiştir. Tuza tolerans yüzdesi $(\%)=$ Tuz uygulamasındaki bitki kuru ağırlığ $1 /$ Kontrol uygulamasındaki bitki kuru ağırlığ x 100 formülüyle belirlenmiştir (Alsabbagh ve ark., 2016). Yaprak, sap ve salkım oranları hasat edilen bitkilerin yaprak, sap ve salkımlarına ayrıldıktan sonra tartılmış ve bitki yaş ağırlığına oranlanarak belirlenmiştir.

Denemede elde edilen veriler SPSS paket programına göre varyans analizleri yapılmış ve ortalamalar Duncan çoklu karşılaştırma testine göre karşılaştırılmıştır.

\section{BULGULAR VE TARTIŞMA}

Çizelge 1 ve 2 incelendiğinde farklı sulama suyu tuzluluklarının ortalaması olarak bitki boyu, bitki yaş ağırlığı, bitki kuru oranı, bitki kuru ağırlığı, tuza tolerans yüzdeleri, yaprak oranı, sap oranı ve salkım oranının sorgum çeşitleri arasında önemli derecede farklılıklar olduğu görülmektedir.

Buna göre; en yüksek bitki boyu $156.51 \mathrm{~cm}$ ile Gözde 80 çeşidinde, bitki yaş ağırlığı $265.39 \mathrm{~g}$ ile Hayday çeşidinde, bitki kuru oranı \% 32.46 ve \% 30.99 ile sirasiyla Gözde-80 ve Nutri Honey çeşitlerinde, bitki kuru ağırlığı 73.92, 73.67, 70.37 ve $70.09 \mathrm{~g}$ ile sirasiyla Rox, Hayday, Leoti ve Early Sumac çeşitlerinde, tuza tolerans yüzdeleri \% 61.69, $\% 61.03$, \% 59.54 ve \% 59.26 ile sirasiyla Rox, Early sumac, Gözde-80 ve Nutri honey çeşitlerinde, yaprak oran $\% 24.23$ ve \% 24.11 ile sırasıyla Nutri honey ve Hayday çeşitlerinde, sap oranı \% 79.99 ile Early sumac çeşidinde, salkım oranı \% 10.51 ile Rox çeşidinde elde edilmiştir. Nitekim yapılan çalışmalarda sorgum çeşitlerinin verim ve verim öğeleri yönünden birbirlerinden önemli derecede farklılık gösterdiği ortaya konulmuştur (İptaş, 1993; Baytekin ve ark., 1995; Gül ve Başbağ , 1999; Akdeniz et al., 2002; Keskin et al, 2005a; Keskin ve ark., 2005b; Parlak ve Parlak, 2005; Çarpıcı et al., 2009; Atış, 2011). 
Çizelge 1. Farklı sulama suyu tuzluluğunun sorgum çeşitleri üzerine etkileri

\begin{tabular}{|c|c|c|c|c|c|c|c|c|}
\hline Çeşit & Kontrol & 3 & 6 & 9 & 12 & 15 & 18 & Çeşit ort. \\
\hline \multicolumn{9}{|c|}{ Bitki Boyu $(\mathrm{cm})$} \\
\hline Rox & 154.60 & 133.20 & 140.80 & 119.40 & 106.00 & 93.00 & 67.40 & $116.34 \mathrm{~cd}$ \\
\hline Early sumac & 158.00 & 171.20 & 141.20 & 135.60 & 107.20 & 91.20 & 122.00 & $132.34 \mathrm{~b}$ \\
\hline Leoti & 165.75 & 153.72 & 124.15 & 90.02 & 87.10 & 86.77 & 62.40 & $109.98 \mathrm{~d}$ \\
\hline Nutri Honey & 183.05 & 141.75 & 160.65 & 113.75 & 103.25 & 90.30 & 94.15 & $126.70 \mathrm{bc}$ \\
\hline Hayday & 178.87 & 164.62 & 148.12 & 138.75 & 110.62 & 80.25 & 77.25 & $128.30 \mathrm{~b}$ \\
\hline Gözde-80 & 213.90 & 181.80 & 193.20 & 161.10 & 141.00 & 121.50 & 83.10 & $156.51 \mathrm{a}$ \\
\hline EC ort. & $175.69 \mathrm{a}$ & $157.7 \mathrm{~b}$ & $151.3 \mathrm{~b}$ & $126.3 \mathrm{c}$ & $109.2 \mathrm{~d}$ & $93.83 \mathrm{e}$ & $84.38 \mathrm{e}$ & \\
\hline \multicolumn{9}{|c|}{ Bitki Yaş Ağırlığı $\left(\right.$ gr bitki $\left.^{-1}\right)$} \\
\hline Rox & 407.49 & 351.09 & 308.67 & 257.76 & 192.24 & 149.15 & 97.42 & $251.97 \mathrm{~b}$ \\
\hline Early sumac & 436.40 & 385.92 & 291.60 & 219.45 & 159.92 & 118.45 & 101.32 & $244.72 b$ \\
\hline Leoti & 481.25 & 410.30 & 283.65 & 213.00 & 158.35 & 115.45 & 81.97 & $249.13 b$ \\
\hline Nutri Honey & 381.01 & 326.92 & 282.10 & 213.36 & 137.43 & 93.37 & 77.62 & $215.97 \mathrm{c}$ \\
\hline Hayday & 510.42 & 417.53 & 316.46 & 269.08 & 162.36 & 108.10 & 72.79 & $265.39 \mathrm{a}$ \\
\hline Gözde-80 & 342.22 & 292.08 & 254.38 & 209.12 & 150.88 & 112.58 & 66.60 & $203.98 \mathrm{~d}$ \\
\hline EC ort. & $426.46 \mathrm{a}$ & $363.9 \mathrm{~b}$ & $289.6 \mathrm{c}$ & $230.2 d$ & $160.19 \mathrm{e}$ & $116.18 \mathrm{f}$ & $82.95 \mathrm{~g}$ & \\
\hline \multicolumn{9}{|c|}{ Bitki Kuru Oranı $(\%)$} \\
\hline Rox & 30.42 & 27.04 & 30.24 & 29.42 & 29.96 & 28.05 & 31.11 & $29.46 b c$ \\
\hline Early sumac & 27.25 & 27.38 & 24.72 & 30.61 & 29.53 & 36.76 & 34.63 & $30.13 \mathrm{~b}$ \\
\hline Leoti & 27.25 & 28.70 & 29.32 & 29.06 & 29.05 & 27.96 & 24.19 & $27.93 \mathrm{c}$ \\
\hline Nutri Honey & 28.94 & 24.86 & 31.03 & 33.72 & 31.08 & 34.13 & 33.18 & $30.99 \mathrm{a} \mathrm{b}$ \\
\hline Hayday & 28.28 & 24.63 & 26.35 & 27.90 & 27.91 & 32.92 & 40.09 & $29.72 \mathrm{~b} \mathrm{c}$ \\
\hline Gözde-80 & 33.42 & 30.04 & 33.24 & 32.42 & 32.96 & 31.05 & 34.11 & $32.46 \mathrm{a}$ \\
\hline EC ort. & $29.26 \mathrm{~cd}$ & $27.11 \mathrm{~d}$ & $29.15 \mathrm{~cd}$ & $30.52 \mathrm{bc}$ & $30.08 \mathrm{bc}$ & $31.81 \mathrm{ab}$ & $32.89 \mathrm{a}$ & \\
\hline \multicolumn{9}{|c|}{ Bitki Kuru A ̆̆ırlığı $\left(\right.$ gr bitki $\left.^{-1}\right)$} \\
\hline Rox & 124.03 & 95.01 & 93.35 & 75.80 & 57.22 & 41.63 & 30.41 & $73.92 \mathrm{a}$ \\
\hline Early sumac & 119.05 & 105.68 & 72.28 & 67.29 & 47.43 & 43.93 & 35.00 & $70.09 \mathrm{ab}$ \\
\hline Leoti & 130.96 & 117.50 & 82.99 & 62.28 & 46.37 & 32.19 & 20.31 & $70.37 \mathrm{ab}$ \\
\hline Nutri Honey & 110.09 & 81.25 & 87.34 & 71.90 & 42.67 & 31.82 & 25.87 & $64.42 \mathrm{c}$ \\
\hline Hayday & 144.31 & 103.18 & 83.67 & 75.12 & 45.13 & 35.16 & 29.19 & $73.67 \mathrm{a}$ \\
\hline Gözde-80 & 114.43 & 87.81 & 84.56 & 67.76 & 49.39 & 34.77 & 22.81 & $65.93 \mathrm{bc}$ \\
\hline EC ort. & $123.81 \mathrm{a}$ & $98.40 \mathrm{~b}$ & $84.03 \mathrm{c}$ & $70.02 \mathrm{~d}$ & $48.03 \mathrm{e}$ & $36.58 \mathrm{f}$ & $27.26 \mathrm{~g}$ & \\
\hline \multicolumn{9}{|c|}{ Tuza Tolerans Yüzdesi (\%) } \\
\hline Rox & 100.00 & 76.96 & 76.61 & 71.63 & 47.44 & 34.49 & 24.70 & $61.69 \mathrm{a}$ \\
\hline Early sumac & 100.00 & 89.71 & 61.51 & 69.18 & 39.62 & 37.47 & 29.71 & $61.03 \mathrm{a}$ \\
\hline Leoti & 100.00 & 90.09 & 63.20 & 52.10 & 35.78 & 24.82 & 15.80 & $54.54 \mathrm{~b}$ \\
\hline Nutri Honey & 100.00 & 74.41 & 79.23 & 69.40 & 39.19 & 29.16 & 23.44 & $59.26 \mathrm{a}$ \\
\hline Hayday & 100.00 & 72.19 & 58.57 & 66.02 & 32.07 & 24.65 & 20.47 & $53.42 \mathrm{~b}$ \\
\hline Gözde-80 & 100.00 & 77.11 & 74.94 & 69.51 & 44.26 & 31.02 & 19.99 & $59.54 \mathrm{a}$ \\
\hline EC ort. & $100.00 \mathrm{a}$ & $80.08 \mathrm{~b}$ & $69.01 \mathrm{c}$ & $66.30 \mathrm{c}$ & $39.73 \mathrm{~d}$ & $30.27 \mathrm{e}$ & $22.37 \mathrm{f}$ & \\
\hline
\end{tabular}

Aynı harflerle gösterilen değerlen arasındaki fark istatistiksel olarak önemli değildir. 
Sulama suyundaki tuzluluk miktarının artmasıyla sorgum çeşitlerinin bitki boyu, bitki yaş ağırlı̆̆ kuru ağırlığı, tuza tolerans yüzdeleri ve salkım oranında azalmalar olurken, bitki kuru oranı, yaprak oranı ve sap oranında ise artmalar görülmüştür (Çizelge 1,2; Şekil $1,2,3,4,5,6,7)$.

Çizelge 2. Farklı sulama suyu tuzluluğunun sorgum çeşitleri üzerine etkileri

\begin{tabular}{|c|c|c|c|c|c|c|c|c|}
\hline Çeşit & Kontrol & 3 & 6 & 9 & 12 & 15 & 18 & Çeşit ort. \\
\hline \multicolumn{9}{|c|}{ Yaprak Oranı (\%) } \\
\hline Rox & 20.20 & 20.16 & 16.08 & 20.50 & 19.37 & 18.75 & 29.95 & $20.57 \mathrm{~b}$ \\
\hline Early sumac & 18.97 & 12.05 & 18.33 & 14.71 & 16.19 & 13.62 & 13.75 & $15.37 \mathrm{~d}$ \\
\hline Leoti & 16.31 & 13.94 & 14.90 & 16.58 & 15.62 & 18.12 & 16.67 & $16.02 \mathrm{~cd}$ \\
\hline Nutri Honey & 17.10 & 20.36 & 23.91 & 25.68 & 25.53 & 28.20 & 28.83 & $24.23 \mathrm{a}$ \\
\hline Hayday & 17.41 & 14.99 & 22.40 & 24.79 & 27.74 & 30.13 & 31.34 & $24.11 \mathrm{a}$ \\
\hline Gözde-80 & 16.28 & 16.23 & 12.67 & 16.19 & 15.55 & 15.18 & 23.93 & $16.57 \mathrm{c}$ \\
\hline EC ort. & $17.71 \mathrm{c}$ & $16.29 \mathrm{~d}$ & $18.05 \mathrm{c}$ & $19.7 \mathrm{~b}$ & $20.00 \mathrm{~b}$ & $20.66 \mathrm{~b}$ & $23.9 \mathrm{a}$ & \\
\hline \multicolumn{9}{|c|}{ Sap Oranı $(\%)$} \\
\hline Rox & 67.86 & 67.22 & 69.19 & 65.77 & 72.36 & 74.48 & 65.41 & $68.90 \mathrm{e}$ \\
\hline Early sumac & 72.67 & 78.84 & 78.90 & 81.85 & 79.96 & 84.09 & 83.61 & $79.99 \mathrm{a}$ \\
\hline Leoti & 74.83 & 74.84 & 77.27 & 78.75 & 79.74 & 80.00 & 80.06 & $77.93 \mathrm{~b}$ \\
\hline Nutri Honey & 73.77 & 73.42 & 71.65 & 72.20 & 73.82 & 69.43 & 68.76 & $71.86 \mathrm{~d}$ \\
\hline Hayday & 70.66 & 71.39 & 69.51 & 69.91 & 69.23 & 67.13 & 66.28 & $69.16 \mathrm{e}$ \\
\hline Gözde-80 & 72.80 & 72.08 & 73.33 & 70.36 & 77.56 & 79.86 & 72.07 & $74.01 \mathrm{c}$ \\
\hline EC ort. & $72.10 \mathrm{~b}$ & $72.96 \mathrm{~b}$ & $73.31 \mathrm{~b}$ & $73.14 b$ & $75.45 \mathrm{a}$ & $75.83 \mathrm{a}$ & $72.70 \mathrm{~b}$ & \\
\hline \multicolumn{9}{|c|}{ Salkım Oranı (\%) } \\
\hline Rox & 11.92 & 12.61 & 14.72 & 13.72 & 8.25 & 6.75 & 5.63 & $10.51 \mathrm{a}$ \\
\hline Early sumac & 8.35 & 9.11 & 2.76 & 3.43 & 3.84 & 2.29 & 2.64 & $4.63 \mathrm{~d}$ \\
\hline Leoti & 8.84 & 11.21 & 7.83 & 4.67 & 4.62 & 1.87 & 3.27 & $6.04 \mathrm{c}$ \\
\hline Nutri Honey & 9.12 & 6.20 & 4.43 & 2.11 & 0.64 & 2.36 & 2.39 & $3.89 \mathrm{~d}$ \\
\hline Hayday & 11.92 & 13.61 & 8.08 & 5.29 & 3.01 & 2.73 & 2.37 & $6.71 \mathrm{c}$ \\
\hline Gözde-80 & 10.91 & 11.67 & 13.99 & 13.44 & 6.88 & 4.96 & 3.99 & $9.41 \mathrm{~b}$ \\
\hline EC ort. & $10.18 \mathrm{a}$ & $10.73 a$ & $8.63 \mathrm{~b}$ & $7.11 \mathrm{c}$ & $4.54 \mathrm{~d}$ & $3.49 \mathrm{e}$ & $3.38 \mathrm{e}$ & \\
\hline
\end{tabular}

Aynı harflerle gösterilen değerlen arasındaki fark istatistiksel olarak önemli değildir.

En uzun boya ulaşan çeşitlerin kontrol grubunda $213.90 \mathrm{~cm}$ ile Gözde- 80 ve $193.20 \mathrm{~cm}$ 'lik bitki boyu ile 6 EC değerinde tuzlu su uygulanan Nutri honey çeşidinde olduğu görülmektedir. Boyu en kısa olan bitkilerin ise 18 EC değerinde $62.40 \mathrm{~cm}$ ile Leoti ve $67.40 \mathrm{~cm}$ 'lik bitki boyu ile Rox çeşidi olmuştur (Şekil 1). En çok bitki yaş ağırlığ 1 tuzlu su uygulanmayan kontrol grubunda 510.42 g ile Hayday çeşidinde olduğu görülmektedir. En az bitki yaş ağırlığı ise $18 \mathrm{EC}$ değerinde $66.60 \mathrm{~g}$ ile
Gözde-80 çeşidi olmuştur (Şekil 2). En çok bitki kuru oranı 18 EC değerinde \% 40.09 ile Hayday çeşidinde, en az bitki kuru oranı ise 3 EC değerinde \% 24.63 ile Hayday çeşidinde olmuştur (Şekil 3). En yüksek bitki kuru ağırlığı $144.43 \mathrm{~g} / \mathrm{bitki}$ ile tuzlu su uygulanmayan Hayday çeşidinde olmuştur. En düşük bitki kuru ağırlığı ise $20.31 \mathrm{~g} \mathrm{bitki}^{-1}$ ile $18 \mathrm{EC}$ değerinde tuzlu su uygulanan Leoti çeşidinde gerçekleşmiştir (Şekil 4). Kontrol uygulaması hariç olmak üzere en yüksek tuza tolerans 
yüzdesi \%90.09 ile Leoti çeşidinde ve $3 \mathrm{EC}$ değerinde tuzlu su uygulanan saksılarda elde edilirken, en düşük tuza tolerans yüzdeleri ise $\% 15.80$ ile $18 \mathrm{EC}$ değerinde tuzlu su uygulanan Leoti çeşidinde gözlemlenmiştir (Şekil 5). En yüksek yaprak oranı \% 31.34 ile 18 EC değerinde tuzlu su uygulanan Hayday çeşidinde elde edilirken, en düşük yaprak oranı \%12.05 ile 3 EC değerinde tuzlu su uygulanan Early sumac çeşidinde elde edilmiştir (Şekil 6). En yüksek sap oranı \%84.09 ile 15 EC değerinde tuzlu su uygulanan Early sumac çeşidinde elde edilirken, en düşük sap oranı $\% 65.41$ ile 18 EC değerinde tuzlu uygulanan Rox çeşidinde elde edilmiştir (Şekil 7). En yüksek salkım oranı \%14.72 ile 6 EC değerinde tuzlu su uygulanan Rox çeşidinde görülmüştür En düşük salkım oranı ise \%0.64 ile $12 \mathrm{EC}$ değerinde tuzlu su uygulanan Nutri honey çeşidinden elde edilmiştir (Şekil 8). Sulama suyundaki tuz yoğunluğunun artmasıyla araştırmada kullanılan tüm sorgum çeşitlerinin bitki boylarında kısalmalar olduğu görülmektedir. Ayrıca bu durum bitki yaş ağırlığı, bitki kuru ağırlığ 1 ve sorgum çeşitlerinin tuza tolerans yüzdelerinde de azalmalara neden olmuştur (Şekil 1, 2, 4 ve 5). Sulama suyu tuz düzeyinin artması bitkilerde bodur büyümeye, yaprakların küçük kalmasına ve kök büyümesinde gerilemeye neden olduğundan dolayı bitkinin boyu ile yaş ve kuru otunda azalmalara neden olmaktadır. Ayrıca artan tuz yoğunluğu bitkinin tuza direncini kırmakta ve tuza toleranslarını düşürmektedir. Nitekim yapılan araştırmalarda da artan miktarda tuzlu su uygulamasının bitkide verim düşüşlerine neden olduğu belirlenmiştir (Francois et al., 1984; Maas et al., 1986; Rivelli et al., 2002; Yurtseven ve ark., 2002; Abid et al., 2003; Parlak ve Parlak, 2005; Mensah et al., 2006; Çarpicı et al, 2009; Kökten et al., 2010; Nawaz et al., 2010; Atış, 2011).

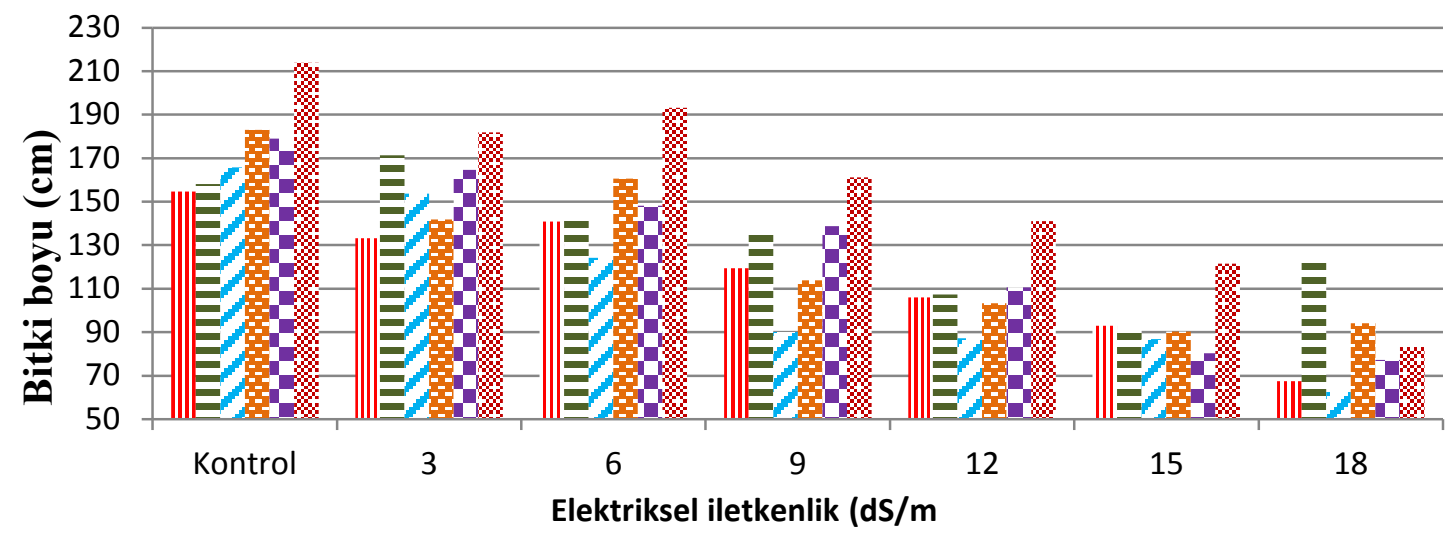

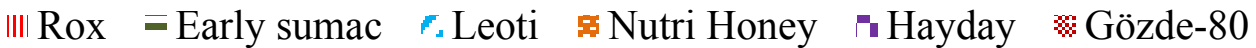

Şekil 1. Farklı sulama suyu tuzluluğunun sorgum çeşitlerinin bitki boyları üzerine etkileri

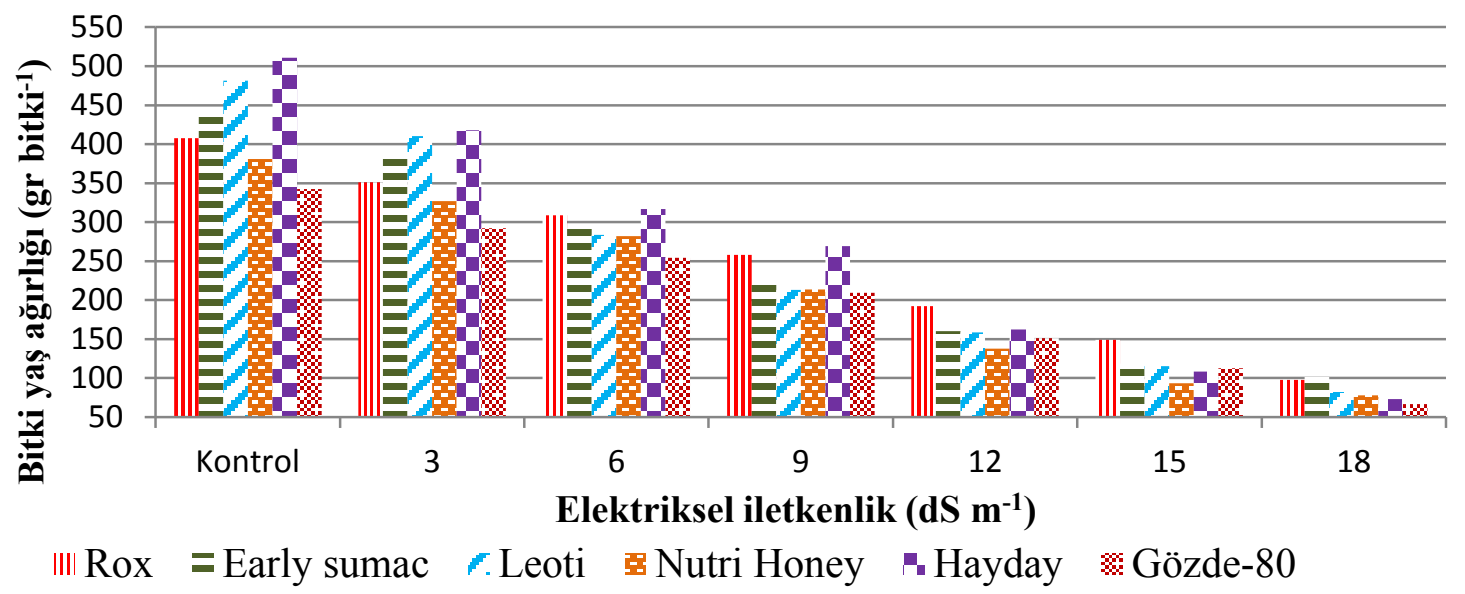

Şekil 2. Farklı sulama suyu tuzluluğunun sorgum çeşitlerinin bitki yaş ağırlığı üzerine etkileri 


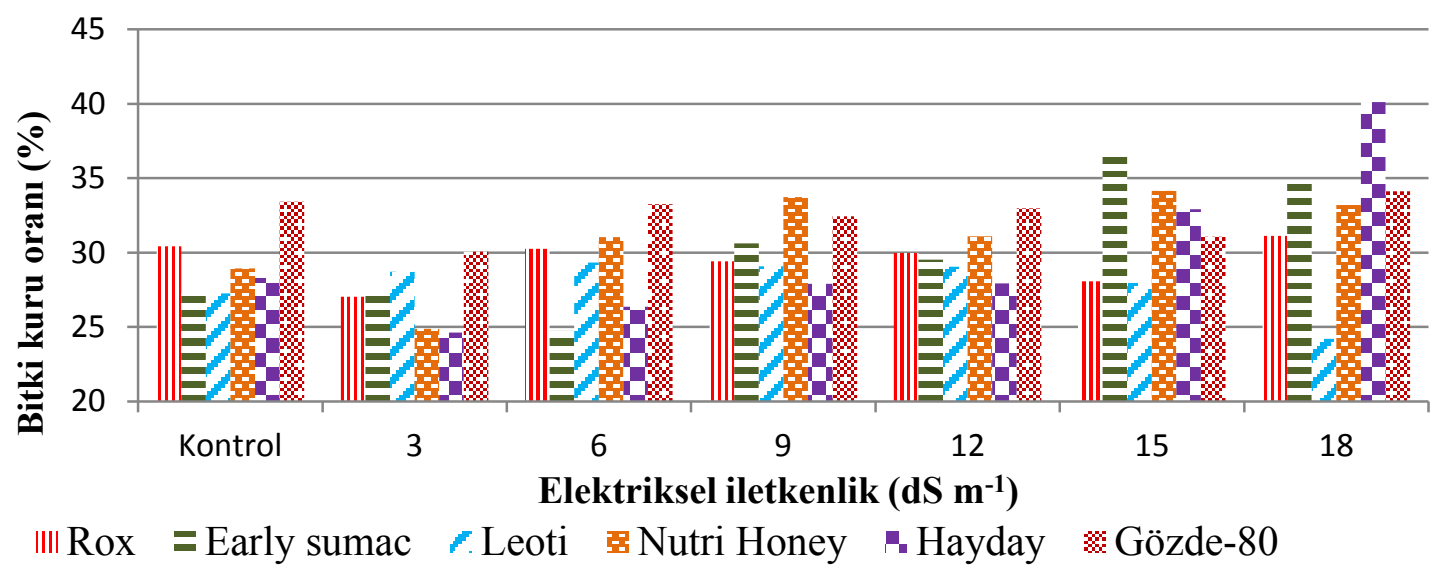

Şekil 3. Farklı sulama suyu tuzluluğunun sorgum çeşitlerinin bitki kuru oranı üzerine etkileri

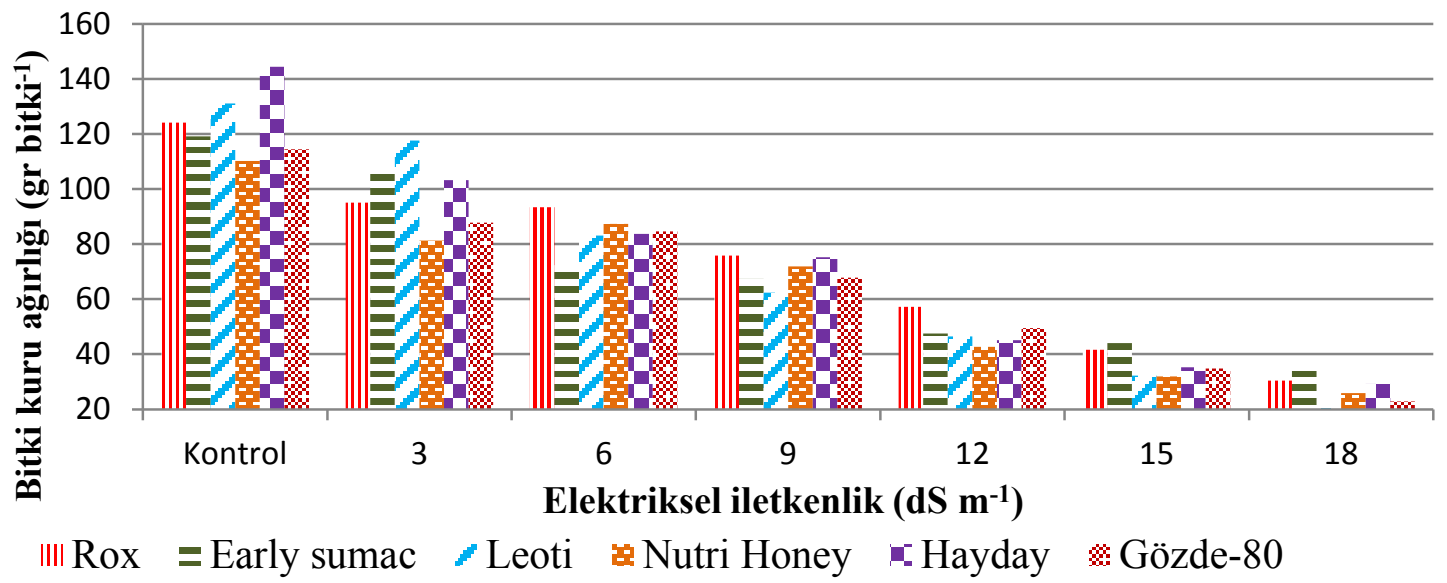

Şekil 4. Farklı sulama suyu tuzluluğunun sorgum çeşitlerinin bitki kuru ağırlığı üzerine etkileri

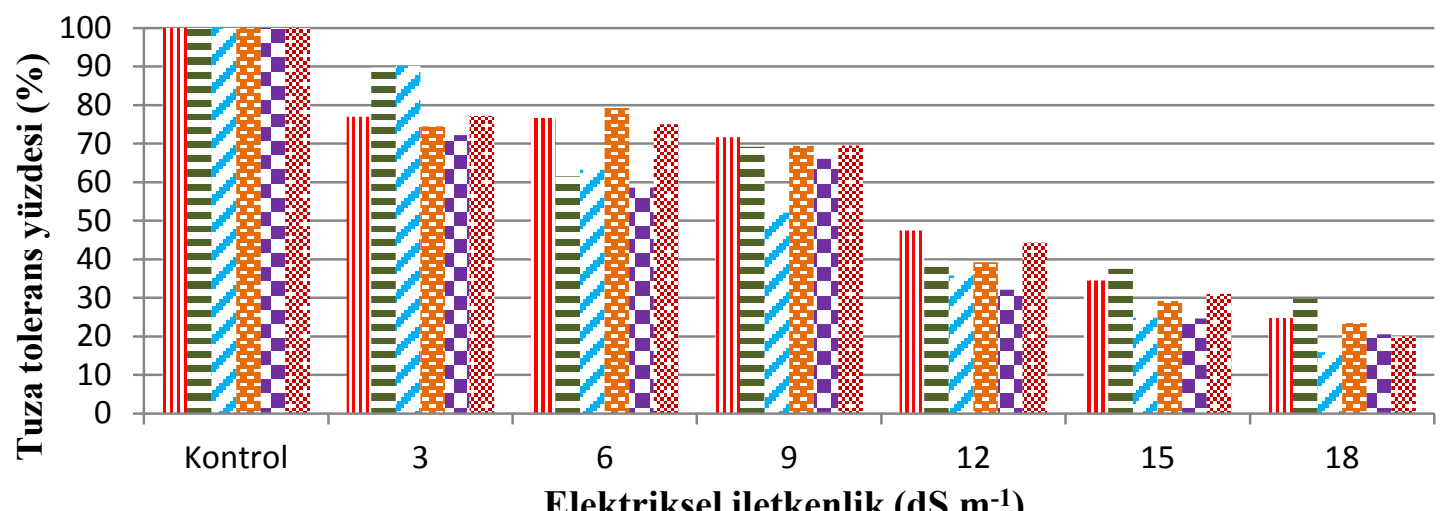

Elektriksel iletkenlik (dS m $\left.{ }^{-1}\right)$

III Rox =Early sumac "L Leoti Nutri Honey Z"Hayday Gözde-80

Şekil 5. Farklı sulama suyu tuzluluğunun sorgum çeşitlerinin tuza tolerans yüzdesi üzerine etkileri 


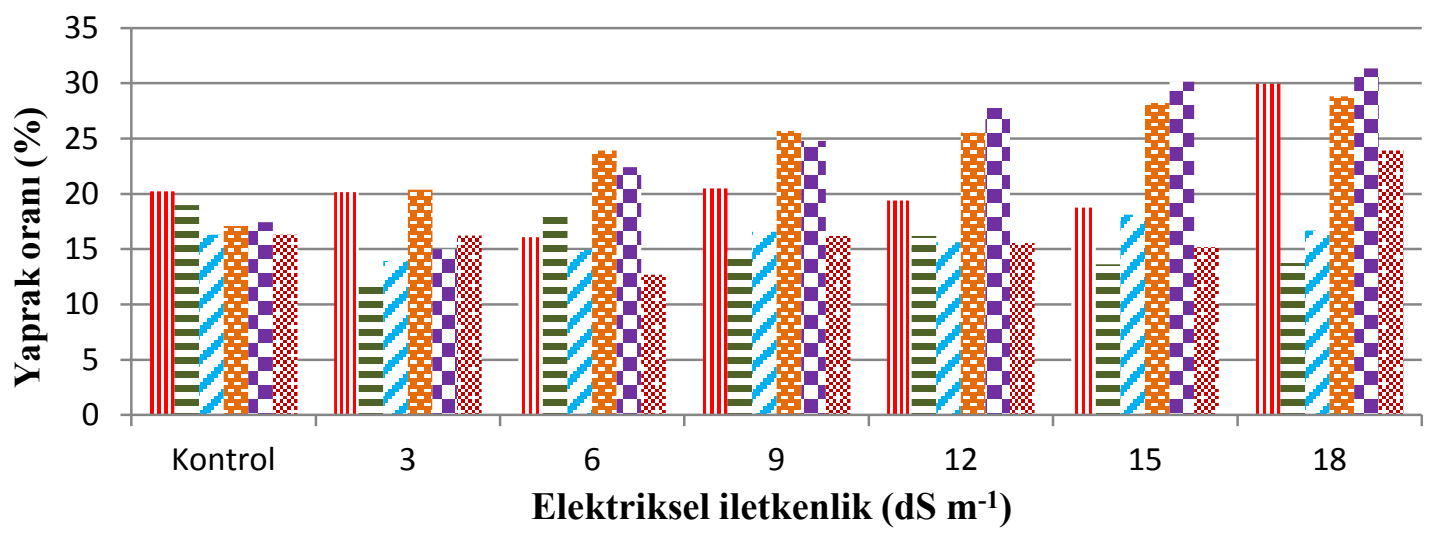

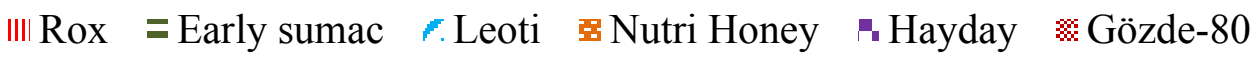

Şekil 6. Farklı sulama suyu tuzluluğunun sorgum çeşitlerinin yaprak oranı üzerine etkileri

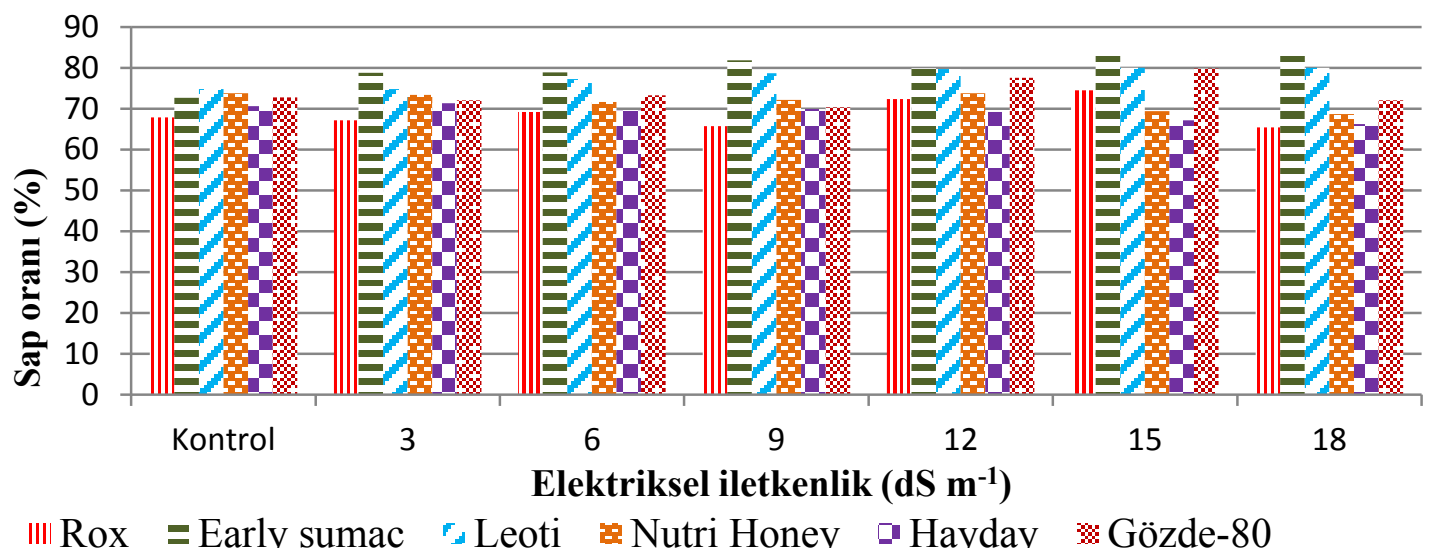

Şekil 7. Farklı sulama suyu tuzluluğunun sorgum çeşitlerinin sap oranı üzerine etkileri

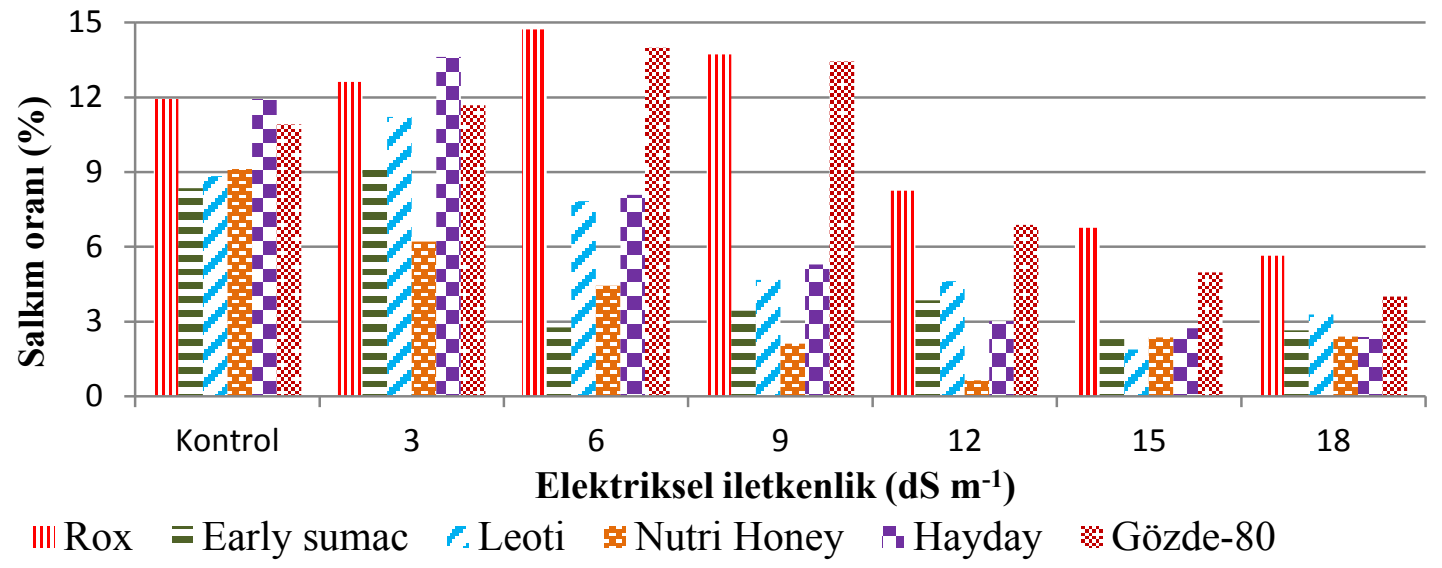

Şekil 8. Farklı sulama suyu tuzluluğunun sorgum çeşitlerinin salkım oranı üzerine etkileri

Sulama suyundaki tuz yoğunluğunun artmasıyla bazı sorgum çeşitlerinin kuru oranlarında bir miktar yükselme olurken, bazı sorgum çeşitlerinde ise azalmalar olmuştur. Kuru oranda en belirgin yükselme
Hayday çeşidinde, en belirgin azalma ise Leoti çeşidinde gerçekleşmiştir (Şekil 3). Sulama suyundaki tuzluluğun artmasıly Rox (18 EC hariç), Leoti, Gözde-80 (18 EC hariç) sorgum çeşitlerinin yaprak oranlarında herhangi 
bir önemli değişiklik olmamıştır. Diğer taraftan sulama suyundaki artan tuzluluk oranı Early Sumac sorgum çeşidinin yaprak oranını düşürürken, Nutri Honey ve Hayday sorgum çeşitlerinin yaprak oranını ise artırmışırı (Şekil 6). Tuzluluğun artmasıyla sorgum çeşitlerinin sap oranlarındaki değişimler farklı olmuştur. Örneğin Early Sumac, Leoti ve Gözde-80 sorgum çeşitlerinde sap oranı artmış, Nutri Honey ve Hayday çeşitlerinde sap oranı düşmüş, Rox sorgum çeşidinde ise sap oranında önemli bir değişiklik olmamıştır (Şekil 7). Sorgum çeşitlerinin salkım oranlarında tuzluluğun artmasına paralel olarak bir azalma gerçekleşmiştir (Şekil 8).

\section{SONUÇ}

Sulama suyu tuzluluğunun artmasıyla bitki boyu, bitki yaş ot ağırlığ 1 , kuru ot ağırlığı, tuza tolerans yüzdeleri ve salkım oranları azalma olurken, kuru ot oranı, yaprak oranı, sap oranı değerlerinde ise artışlar olmuştur. Sorgum çeşitlerine uygulanan yedi farklı tuzlu su uygulamasının ortalamasına göre incelenen verim ve verim öğeleri yönünden çeşitler arasında

\section{KAYNAKLAR}

Abid M, Hassan A, Ghafoor A, Javed K, 2003. Brackish Water for İrigation: I. Effects on Yield of Wheat and Sorghum in Wheat-Sorghum Crop Rotation and Properties of The Rasulpur Soil Series. International Journal of Agriculture and Biology, 5(3): 367-376.

Akdeniz H, Yılmaz İ, Keskin B, Arvas Ö, 2002. The Effects of Different Nitrogen Levels on Yield and Yield Compenents of Some Silage Sorghum (Sorghum vulgare L.) Varieties Grown Under Irrigated Conditions in Van Turkey. Turk J. of Field Crops, 7: 52-60.

Alsabbagh MHA, Türkmen Ö, Seymen M, 2016. Citrillus lanatus var. lanatus ve Citrillus lanatus var. citroides kaynaklı bazı karpuz genotiplerinin tuza tolerans düzeylerinin belirlenmesi. Yüzüncü Yıl Üniversitesi Fen Bilimleri Enstitüsü Dergisi, 21(1):24-38.

Ashraf M, 1994. Breeding for salinity tolerance in plants. Critical Reviews in Plant Sciences, 13(1): 17-42.

Atış İ, 2011. Bazı Silajlık Sorgum (Sorghum bicolor L. Moench) Çeşitlerinin Çimlenmesi ve Fide Gelişimi Üzerine Tuz Stresinin Etkileri. Süleyman Demirel Üniversitesi Ziraat Fakültesi Dergisi, 6(2): 58-67.

Baytekin H, Gül İ, Bengisu G, 1995. Harran ovası sulu şartlarında ikinci ürün olarak yetiştirilen silaj sorgumda farklı azot dozlarının verim ve bazı tarımsal karakterlere etkisi. Harran Üniversitesi Ziraat Fakültesi Dergisi, 1(3): 212-216. önemli farklılıklar gözlenmiştir. Buna göre, en yüksek bitki boyu ve bitki kuru oranı Gözde-80 çeşidinde, bitki yaş ağırlığı Hayday çeşidinde, tuza tolerans yüzdesi Rox, Early Sumac, Gözde-80 ve Nutri honey çeşitlerinde, salkım oranı Rox çeşidinde, kuru ot ağırlı $\breve{g} 1$ Rox ve Hayday çeşidinde, yaprak oranı Nutri honey ve Hayday çeşitlerinde, sap oranı Early sumac çeşidinde bulunmuştur.

Sorgum çeşitlerine yüksek oranlarda tuzlu su uygulaması yapılmasına rağmen en yüksek tuzlu su uygulamasında bile önemli sayılabilecek bir yeşil aksam gelişmesi gerçekleşmiştir. Yapılan araştırmaların birçoğunda sorgum çeşitlerinin orta derecede tuzluğa dayanaklı olduğunun belirlenmesi ve toprakların önemli bir kısmının az ve orta tuzlu olduğu düşünüldüğünde sorgum çeşitlerinin bu tuzlu alanlarda yetiştiriciliğinin yapılması uygun olacaktır. Tuzlu su seviyesinin 3 EC olduğu bölgelerde Leoti ve Early sumac, tuzlu suyun EC'sinin 6,9 ve 12 seviyelerinde olduğu bölgelerde Rox, tuzlu suyun EC'sinin 15 ve 18 olduğu bölgelerde ise Early sumac ve Rox çeşitlerinin tercih edilmesi uygun olacaktır.

Beltran JM, Manzur CL, 2005. Overview of salinityproblems in the world and FAO strategies to address the problem. Proceedings of the international salinity forum, 311-313s, April 2005, Riverside, California.

Berenguer MJ, Faci JM, 2001. Sorghum (Sorghum bicolor L. Moench) Yield Compensation Processes Under Different Plant Densities and Variable Water Supply. European Journal of Agronomy, 15(1): 43-55.

Çarpıcı EB, Çelik N, Bayram G, 2009. Effects of Salt Stress on Germination of Some Maize (Zea mays L.) Cultivars. African Journal of Biotechnology, 8(19): 4918-4922.

Epstein E, 1985. Salt-Tolerante Crops: Origins, Development, and Prospects of The Concept. Plant and Soil, 89(1/3): 187-198.

Francois LE, Donovan T, Maas EV, 1984. Salinity effects on Seed Yield, Growth, and Germination of Grain Sorghum. Agronomy Journal, 76:741-744.

Fribourg HA, Duck BN, Culvahouse EM, 1976. Forage Sorghum Yield Components and Their in vivo Digestibility. Agronomy Journal, 68(2): 361-365.

Gül İ, Başbağ M, 1999. Diyarbakır sulu koşullarında ikinci ürün olarak yetiştirilen Silaj sorgum, Sorgum-Sudan otu Melezi, Sudan otu Çeşitlerinde Verim ve Verim Özelliklerinin İncelenmesi. Türkiye 3. Tarla Bitkileri Kongresi. Cilt:3, 306311, Çayır-Mer'a Yem Bitkileri ve Yemeklik Tane Baklagiller, Adana. 
Güngör Y, Erözel Z, 1994. Drenaj ve Arazi Islahı. Ders Kitabı. Ankara Ün. Ziraat Fak. Yayınları, yayın no:1341, Ders Kitab1:389, Ankara.

İptaş S, 1993. Tokat Yöresinde Sorgum ve Sorgum x Sudan Otu Melezi Çeşitlerinde Yararlanma İmkanları. Tarla Bitkileri Çayır-Mer'a ve Yem bitkileri Kongresi. 341-351s, 21-22 Eylül 1993, İzmir.

Keskin B, Yılmaz İH, Akdeniz H, 2005a. Sorgum x Sudan Otu Melezi (Sorghum bicolor x Sorghum sudanense Mtapf.) Çeşitlerinde Hasat Zamanının Verim ve Verim Unsurlarına Etkisi. Atatürk Üniv. Ziraat Fak. Dergisi, 36(2): 145-150.

Keskin B, Y1lmaz İH, Karsl1 MA, Nursoy H, 2005b. Effects of Urea or Urea Plus Molasses Supplementation to Silages with Different Sorghum Varieties Harvested at the Milk Stage on the Quality and In Vitro Dry Matter Digestibility of Silages. Turk J Vet Anim Sci, 29:1143-1147.

Khalili A, Akbari N, Chaichi MR, 2008. Limited Irrigation and Phosphorus Fertilizer Effects on Yield and Yield Components of Grain Sorghum (Sorghum bicolor L. var. kimia). American-Eurasian J. Agric. and Environ. Sci., 3(5): 697-702.

Kökten K, Karaköy T, Bakoğlu A, Akçura M, 2010. Determination of Salinity Tolerance of Some Lentil (Lens culinaris M.) Varieties. Journal of Food, Agriculture \& Environment, 8(1): 140- 143.

Maas EV, Poss JA, Hoffman GJ, 1986. Salinity Sensitivity of Sorghum at Three Growth Stages. Irrigation Science, 7(1): 1-11.

Mensah JK, Akomeah PA, Ikhajiagbe B, Ekpekurede EO, 2006. Effects of salinity on germination, growth and yield of five groundnut genotypes. African Journal of Biotechnology, 5(20): 1973-1979.

Nawaz K, Talat A, Iqra, Hussain K, Majeed A, 2010. Induction of Salt Tolerance in Two Cultivars of Sorghum (Sorghum bicolor L.) by Exogenous Application of Proline at Seedling Stage. World Applied Sciences Journal, 10(1): 93-99.
Parlak M, Parlak AÖ, 2005. Sulama Suyu Tuzluluk Düzeylerinin Silajlık Sorgumun (Sorghum bicolor (L.) Moench) Verimine ve Toprak Tuzluluğuna Etkisi. Tarım Bilimleri Dergisi, 12 (1): 8-13.

Pholsen S, Kasikranan S, Pholsen P, Suksri A, 1998. Dry Matter Yield, Chemical Components and Dry Matter Degradability of Ten Sorghum Cultivars (Sorghum bicolor L. Moench) Grown on Oxic Paleustult Soil. Pakistan Journal of Biological Sciences, 1(3): 228-231.

Poonia SR, Pal R, 1979. The effect of organic manuring and water quality on water transmission parameters and sodication of a sandy loam soil. Agricultural Water Management, 2(2):163175 .

Rivelli AR, Lovelli S, Nardiello I, Perniola M, Gherbin P, 2002. Growth and Yield Response of Paper Sorghum to Irrigation With Saline Water (Sorghum bicolor (L.) Moench x Sorghum dochna var. technicum-Basilicata). Rivista di Agronomia, 36(4): 333-338.

Sağlamtimur T, Tansı V, Baytekin H, 1998. Yem Bitkileri Yetiştirme. Çukurova Üniversitesi Ziraat Fakültesi Ders Kitabı No: 74. Adana.

Shannon MC, 1978. Testing Salt Tolerance Variability Among Tall Wheatgrass Lines. Agronomy Journal, 70(5): 719-722.

Skerman PJ, Riveros F, 1990. Tropical Grasses. FAO Plant Production and Protection Series No:23, pp 695-697, Rome

Temel S, Keskin B, Şimşek U, Yilmaz İH, 2015. Performance of Some Forage Grass Species in Halomorphic Soil. Turkish Journal of Field Crops, 20(2): 131-141.

Yurtseven E, Çaycı G, Sevimay CS, Öztürk A, Parlak M, Yalçın L, 2002. Tuzluluk ve Su Miktarlarının Macar Fiği (Vicia pannonica Crantz) Verimi ve Toprak Tuzluluğuna Etkisi: I. Yıkama Uygulanmayan Koşul. Tarım Bilimleri Dergisi, 8(1): 1-6. 